\title{
Inflammatory Markers and Haptoglobin Polymorphism in Saudi with Non-insulin-dependent Diabetes Mellitus
}

\author{
Abdelmarouf Mohieldein ${ }^{1}$, Mohammad Alzohairy ${ }^{1}$, Marghoob Hasan ${ }^{1}$ \& Amjad A. Khan ${ }^{2}$ \\ ${ }^{1}$ Department of Medical Laboratories, College of Applied Medical Sciences, Qassim University, Buraidah, \\ Saudi Arabia \\ ${ }^{2}$ Department of Optometry, College of Applied Medical Sciences, Qassim University, Buraidah, Saudi Arabia \\ Correspondence: Abdelmarouf Mohieldein, Department of Medical Laboratories, College of Applied Medical \\ Sciences, Qassim University. P.O. Box 6699, Buraidah 51452, Saudi Arabia. Tel: 966-6-380-0050 Ext. 4173. \\ E-mail: mabdelmarouf@hotmail.com
}

Received: September 27, 2012 Accepted: October 16, 2012 Online Published: November 11, 2012

doi:10.5539/gjhs.v5n1p135 URL: http://dx.doi.org/10.5539/gjhs.v5n1p135

The research is financed by the Scientific Research Deanship at Qassim University, Saudi Arabia. No. SR-D-010-234

\begin{abstract}
Objectives: Haptoglobin ( $\mathrm{Hp}$ ) polymorphism associated with clinical evolution of several inflammatory diseases and considered as a predictive factor for development of diabetes complications. We designed the present study to investigate the frequency distribution of $\mathrm{Hp}$ phenotypes among Saudi with non-insulin-dependent diabetes mellitus compared to healthy nondiabetic subjects. Moreover, we explored the possibility of relationship between serum levels of inflammatory markers (namely, high-sensitive C-reactive proteins " $h s$-CRP", interleukin (IL)-6, and Hp) and Hp phenotypes. Methods: In the present case-control study, we enrolled 60 type 2 diabetic patients as the study group and 60 healthy subjects as the control group. We assayed serum levels of Hp and $h s$-CRP by immunoturbidimetric method; while IL-6 was measured by ELISA. Native polyacrylamide gel electrophoresis was used for determination of Hp phenotypes. Results: In type 2 diabetics, serum concentrations of IL-6, $h s$-CRP, and Hp were significantly elevated and correlated to body mass index. Moreover, there was a significant correlation between plasma glucose level and $\mathrm{Hp}(\mathrm{r}=0.577, \mathrm{p}=0.000)$, IL-6 $(\mathrm{r}=0.448, \mathrm{p}=0.000)$, and $h s$-CRP $(\mathrm{r}=0.380, \mathrm{p}=0.001)$. In addition, data demonstrated a positive correlation between HbA1c and Hp $(\mathrm{r}=0.521, \mathrm{p}=0.000)$, IL-6 $(\mathrm{r}=0.420, \mathrm{p}=0.001)$, and $h s$-CRP $(\mathrm{r}=0.353, \mathrm{p}=0.008)$. Hp 2-1 phenotype predominated among subjects in both study and control groups. No significant association between Hp phenotypes with any of the investigated inflammatory markers was documented. Conclusion: Inflammation may represent the link between type 2 diabetes and obesity. Hp 2-1 was the predominant phenotype among Saudi type 2 diabetics as well as healthy subjects. In addition to Hp; other possible genetic polymorphisms like CRP may have its effect on diabetes through different mechanisms.
\end{abstract}

Keywords: C-reactive protein, interleukin-6, haptoglobin, acute phase proteins, haptoglobin phenotypes, type 2 diabetes, non-insulin-dependent diabetes mellitus

\section{Introduction}

Diabetes Mellitus (DM) is one of the main threats to human health in this century (Schwarz et al., 2007). Expert Committee proposed two major classes of DM and named them, insulin-dependent diabetes mellitus (IDDM, type 1 diabetes) and non-insulin-dependent diabetes mellitus (NIDDM, type 2 diabetes) (2002). In Saudi Arabia; DM has become more apparent in the last two decades as a result of dramatic changes in the Saudi population lifestyle typified by unhealthy dietary habits that rich in both sugars and fat, sedentary lifestyle, and high rates of obesity (Mohieldein et al., 2011).

Insulin resistance (IR) and progressive pancreatic beta cell failure are key factors in the development of non-insulin-dependent diabetes mellitus (Maiese et al., 2010). Inflammation has been hypothesized to be associated with IR and precede the development of clinically overt diabetes (Pradhan et al., 2002). Moreover, the possession of a particular phenotype may offer some protection against the development of a variety of common 
disorders including diabetes (Dasgupta et al., 2008).

Haptoglobin (Hp), a hepatocyte derived serum $\alpha$-2-Sialoglycoprotein, is a positive acute phase reactant (Wobeto et al., 2009; Mishra et al., 2010). In man, there are two common alleles for Hp denoted 1 and 2, and correspondingly, three different possible phenotypes (Hp1-1, Hp2-1, and Hp2-2) which have significant structural and functional differences (Vitalis et al., 2011). The Hp 2 allele protein product appears to be an inferior antioxidant and anti-inflammatory compared with the $\mathrm{Hp} 1$ allele protein product. Moreover, $\mathrm{Hp} 1$ is more efficient both in preventing heme release from the $\mathrm{Hp}-\mathrm{Hb}$ complexes and in promoting uptake by the CD163 macrophage receptor (Quaye, 2008; Costacou et al., 2008; A'lvarez-Blasco et al., 2009). Hp polymorphism has been demonstrated to be associated with the prevalence and clinical evolution of many inflammatory diseases (Delanghe \& Langlois, 2002). In addition, it has been demonstrated that Hp polymorphism is predictive of the development of various microvascular and macrovascular complications of diabetes (Burbea et al., 2004).

To our knowledge, there is no study conducted to determine the genetic predisposition of Saudi type 2 diabetics according to Hp polymorphism. We designed the present study to investigate the frequency distribution of Hp phenotypes among Saudi with non-insulin-dependent diabetes mellitus compared to healthy nondiabetic subjects. Moreover, a possible relationship between serum levels of inflammatory markers (high-sensitive C-reactive proteins "hs-CRP", interleukin (IL)-6, Hp) and Hp phenotypes was explored.

\section{Patients \& Methods}

\subsection{Study Design \& Subjects}

This case - control study was conducted on a group of type 2 diabetic patients ( $n=60 ; 22$ males, 38 females) attended at the diabetes clinic, King Fahd Specialist Hospital, Qassim. Diabetes was defined by fasting blood glucose $\geq 7.0 \mathrm{mmol} / \mathrm{L}(126 \mathrm{mg} / \mathrm{dL})$, the use of hypoglycemic agents, or both. Sixty apparently healthy subjects were recruited from public places to represent the control group. They were neither had been diagnosed as having diabetes nor use hypoglycaemic medication.

\subsection{Blood Sampling}

Venous blood sample collected from each subject after informed consent in one heparinized vacutainer (4 ml) and one plain vacutainer $(4 \mathrm{ml})$ to obtain plasma and serum respectively. All blood tubes were maintained at $4^{0} \mathrm{C}$ during transportation to the laboratory. After centrifugation at $3000 \mathrm{rpm}$ for $15 \mathrm{~min}$, aliquots of plasma and serum were stored at $-80^{\circ} \mathrm{C}$ until analysis.

\subsection{Hp Phenotyping}

Hp phenotyping was performed by little modification of the method Linke as we described elsewhere (Hasan et al., 2012). Briefly; using a protein vertical mini-gel electrophoresis system (Bio-Rad mini protean III device; USA), total polyacrylamide concentrations of $7.0 \%$ and $4.0 \%$ were prepared respectively for separation and stacking gels of native-PAGE. Hp phenotype bands (Wursters blue) were identified by staining with TMPD (N, N.N'.N'-tetramethylphenylenediamine).

\section{$2.4 h s-C R P \&$ Hp Assay}

Serum concentrations of $h s$-CRP and Hp were assayed by a latex immunoturbidimetric method using Turbi Quick analyzer (vital Diagnostics, Italy). The linearity limits up to $5 \mathrm{mg} / \mathrm{L}$ and up to $250 \mathrm{mg} / \mathrm{dL}$ for $h s$-CRP and Hp respectively. Analysis was done according to manufacturer instructions.

\subsection{IL-6 Assay}

A quantitative sandwich enzyme-linked immunosorbent assay (ELISA) method was performed to determine serum IL-6 concentrations using commercial kits purchased from USCN LIFE, China. Calibration curve was prepared from standards with concentrations of $0.156,0.312,0.625,1.25,2.5,5.0,10.0 \mathrm{ng} / \mathrm{ml}$. The color change was measured spectrophotometrically at $450 \mathrm{~nm}$ using bioMerieux Reader 250 version 2.0.5.

\subsection{Estimation of Blood Glucose and HbAlc}

Plasma glucose levels were determined by end-point enzymatic method (Glucose oxidase-glucose peroxidase) using kits manufactured by Human Diagnostics, Wiesbaden, Germany.

Glycated haemoglobin (HbA1c) was measured from whole blood by Latex immunoturbidimetric method using commercially available kit supplied by Vital Diagnostic, Italy. 


\subsection{Measurement of BMI}

Body weight and height were recorded for each subject. Body mass index (BMI) was calculated as weight (in kilograms) divided by height (in metres) squared. The WHO classification for BMI was used to determine the degree of obesity (World Health Organ Tech Rep Ser, 1995). Subjects were categorized as normal if BMI was less than $25 \mathrm{~kg} / \mathrm{m}^{2}$, overweight if BMI was between $25-29.9 \mathrm{~kg} / \mathrm{m}^{2}$, and obese if BMI was greater than or equal to $30 \mathrm{~kg} / \mathrm{m}^{2}$.

\subsection{Statistical Analysis}

The data analyzed using the statistical package for social sciences (SPSS) software (version 13, Chicago, IL, USA). Results expressed as mean $\pm \mathrm{SD}$ or number (percent) where appropriate. Comparison of continuous variables between patients and control subjects was performed with student t-test and $p$ values $<0.05$ considered as statistically significant. Pearson's correlation was used to test if the examined inflammatory markers (Hp, IL-6, $h s$-CRP) were correlated with age, blood glucose, and HbAlc. To detect whether Hp phenotypes distribution was in agreement with Hardy-Weinberg equilibrium; we determined Chi-square test. Values of $p>0.05$ were considered to be in Hardy-Weinberg equilibrium.

\subsection{Ethical Consideration}

The protocol of this study was approved by the institutional review board of Deanship of Scientific Research, Qassim University, Saudi Arabia. Participation was voluntary and verbal consent was acquired from each participant prior to sample collection. Confidentiality of all participants was maintained as no names were requested.

\section{Results}

\subsection{Characteristics of the Study Participants}

This study recruited 60 type 2 diabetics (study group) and 60 healthy nondiabetic subjects (control group). Most of the participants in both groups were overweight or obese. The patients characterized by significantly ( $\mathrm{p}=$ 0.000 ) higher blood glucose and glycated haemoglobin levels compared to controls. The demographic and clinical characteristics of all subjects are summarized in Table1.

Table 1. Demographic and clinical characteristics of the study participants, comparing type 2 diabetic patients to healthy (nondiabetic) subjects

\begin{tabular}{llll}
\hline Variable & $\begin{array}{l}\text { Patients } \\
\mathrm{n}=60\end{array}$ & $\begin{array}{l}\text { Controls } \\
\mathrm{n}=60\end{array}$ & $\mathrm{p}$-value \\
\hline Gender (male /female) & $22 / 38$ & $31 / 29$ & .098 \\
Age (yr) & $50.59 \pm 9.2$ & $45.98 \pm 9.9$ & $.013^{*}$ \\
Weight $(\mathrm{kg})$ & $80.3 \pm 17.4$ & $75.1 \pm 15.2$ & .083 \\
Height $(\mathrm{cm})$ & $160.9 \pm 5.5$ & $159.7 \pm 14.6$ & .572 \\
BMI $\left(\mathrm{kg} / \mathrm{m}^{2}\right)$ & $31.0 \pm 6.8$ & $29.6 \pm 6.4$ & .227 \\
Blood Glucose (mmol/1) & $10.9 \pm 4.4$ & $5.5 \pm 1.9$ & $.000^{*}$ \\
HbA1c $(\%)$ & $8.5 \pm 2.1$ & $5.0 \pm 1.4$ & $.000^{*}$ \\
Duration of DM (years) & $9.53 \pm 6.2$ & ---- & $\ldots \ldots$. \\
\hline
\end{tabular}

Abbreviations: BMI, body mass index; DM, diabetes mellitus; HbA1c, glycated haemoglobin

Data presented as mean \pm SD for all variables

* p-value $<0.05$; compared type 2 diabetic patients to nondiabetic healthy subjects

\subsection{Markers of Inflammation}

Serum levels of the inflammatory markers (IL-6, hs-CRP, Hp) were significantly increased $(\mathrm{p}=.000, .019$, and .000 respectively) in type 2 diabetics compared to control subjects. Moreover, the increase in the concentrations of the aforementioned inflammatory markers ( $h s$-CRP and Hp) was BMI dependent as shown in Tables $2 \& 3$. 
Table 2. Serum levels of IL-6, hs-CRP, and Hp in types 2 diabetic patients compared to healthy control subjects $($ Mean $\pm \mathrm{SD})$

\begin{tabular}{llll}
\hline analyte & Patients $(\mathrm{n}=60)$ & Controls $(\mathrm{n}=60)$ & $p$-value \\
\hline IL-6 $(\mathrm{ng} / \mathrm{ml})$ & $7.855 \pm 1.2$ & $4.955 \pm 1.7$ & $.000^{*}$ \\
$h s$-CRP $(\mathrm{mg} / \mathrm{l})$ & $2.09 \pm 0.8$ & $1.70 \pm 0.7$ & $.015^{*}$ \\
$\mathrm{Hp}(\mathrm{mg} / \mathrm{dl})$ & $120.15 \pm 14.7$ & $84.72 \pm 13.0$ & $.000^{*}$ \\
\hline
\end{tabular}

Abbreviations: IL-6: interleukin 6; $h s$-CRP: high sensitive C-reactive protein; Hp: haptoglobin.

* P-value $<0.05$; $\mathrm{p}$ value compared diabetic patients to healthy nondiabetic controls

Table 3. Serum levels of inflammatory markers (Hp, $h s$-CRP, and IL-6) in types 2 diabetic patients related to different BMI categories (Mean \pm SD)

\begin{tabular}{llll}
\hline BMI $\left(\mathrm{kg} / \mathrm{m}^{2}\right)$ & $\mathrm{Hp}(\mathrm{mg} / \mathrm{dL})$ & $h s$-CRP $(\mathrm{mg} / \mathrm{L})$ & IL-6 $(\mathrm{ng} / \mathrm{mL})$ \\
\hline$<25(\mathrm{n}=15)$ & $108.92 \pm 17.4$ & $1.31 \pm 0.242$ & $7.06 \pm 0.41$ \\
$25-29.9(\mathrm{n}=22)$ & $120.83 \pm 12.1\left(\mathrm{p}^{1}=0.038^{*}\right)$ & $2.15 \pm 0.63\left(\mathrm{p}^{1}=0.004^{*}\right)$ & $7.80 \pm 1.17\left(\mathrm{p}^{1}=0.250\right)$ \\
$\geq 30(\mathrm{n}=23)$ & $122.74 \pm 18.6\left(\mathrm{p}^{2}=0.036^{*}\right)$ & $2.26 \pm 0.85\left(\mathrm{p}^{2}=0.007^{*}\right)$ & $8.05 \pm 1.2\left(\mathrm{p}^{2}=0.134\right)$ \\
\hline
\end{tabular}

Abbreviations: IL-6: interleukin 6; $h s$-CRP: high sensitive C-reactive protein; Hp: haptoglobin; BMI, body mass index * P-value $<0.05$;

p1 value compared the inflammatory marker in diabetic patients with BMI category (25-29.9) to those diabetics with BMI less than 25 p2 value compared inflammatory marker in diabetic patients with BMI category ( $\geq 30)$ to those diabetics with BMI less than 25

\subsection{Relationship between Inflammatory Markers and Selected Variables (age, blood glucose, and HbA1c) in Type 2 Diabetics}

A positive correlation was found between blood glucose and levels of $h s$-CRP $(\mathrm{r}=0.380, \mathrm{P}=.001), \mathrm{Hp}(\mathrm{r}=$ $0.577, \mathrm{P}=.000)$, and IL-6 $(\mathrm{r}=0.448, \mathrm{P}=.000)$. Moreover, Pearson's correlation analyses showed significant associations of HbAlc with levels of $h s-\mathrm{CRP}(\mathrm{r}=0.353, \mathrm{P}=.008), \mathrm{Hp}(\mathrm{r}=0.521, \mathrm{P}=.000)$, and IL-6 $(\mathrm{r}=0.420$, $\mathrm{P}=.001)$. Although of a positive correlation demonstrated between age and $h s$-CRP $(\mathrm{r}=0.226, \mathrm{P}=.043)$, there was no significant association between age and Hp or Il-6 ( $p>0.05)$. The set of correlation coefficients and $\mathrm{P}$-values for the inflammatory markers, age, blood glucose, and HbAlc is shown in Table 4.

Table 4. The correlations between inflammatory markers (Hp, IL-6, hs-CRP) and selected variables (age, Blood Glucose, and $\mathrm{HbA1c}$ ) in type 2 diabetics

\begin{tabular}{lllllll}
\hline & Hp $(\mathrm{mg} / \mathrm{dl})$ & \multicolumn{2}{l}{ IL-6 $(\mathrm{ng} / \mathrm{ml})$} & \multicolumn{2}{l}{$h s$-CRP $(\mathrm{mg} / \mathrm{l})$} \\
\hline Age & $r=0.200$ & $p=.069$ & $r=0.115$ & $p=.376$ & $r=0.226$ & $p=.043^{*}$ \\
Blood glucose & $r=0.577$ & $p=.000^{*}$ & $r=0.448$ & $p=.000^{*}$ & $r=0.380$ & $p=.001^{*}$ \\
$\mathrm{HbA}_{\mathrm{cc}}$ & $r=0.521$ & $p=.000^{*}$ & $r=0.420$ & $p=.001^{*}$ & $r=0.353$ & $p=.008^{*}$ \\
\hline
\end{tabular}

Abbreviations: IL-6: interleukin 6; $h s$-CRP: high sensitive C-reactive protein; Hp: haptoglobin; HbAlc: Glycated haemoglobin

* P-value $<0.05$

\subsection{Haptoglobin Phenotype Distribution}

Frequencies of Hp phenotypes, Hp1 allele, and Hp 2 allele were in Hardy-Weinberg equilibrium ( $\mathrm{p}>0.05$ ) for patients and control subjects. For Saudi type 2 diabetics, the Hp 1 allele frequency was .513 and for Hp2 allele was .487; while for control subjects it was .534 and .467 for Hp 1 allele and Hp2 allele respectively. Hp 2-1 was the most frequent phenotype among Saudi type 2 diabetics as well as healthy subjects $(62.5 \%$ and $56.7 \%$ respectively). Data illustrated in table 5. 
Table 5. Distribution of Hp phenotype and Hp alleles frequency (Hp1 allele \& Hp2 allele) in Saudi types 2 diabetics and in healthy nondiabetic subjects. Hp phenotypes expressed as number (\%)

\begin{tabular}{|c|c|c|c|c|c|c|c|}
\hline \multirow[t]{3}{*}{ Group } & \multicolumn{3}{|c|}{ Hp phenotype } & \multicolumn{2}{|c|}{ Hp allele frequency } & \multirow[t]{3}{*}{${ }^{2}-$ test } & \multirow[t]{3}{*}{$p$-value } \\
\hline & $\mathrm{Hp}$ & $\mathrm{Hp}$ & $\mathrm{Hp}$ & Hp1 allele & Hp2 allele & & \\
\hline & $1-1$ & $2-1$ & $2-2$ & frequency & frequency & & \\
\hline Patients $(n=60)$ & $14(23.3)$ & $34(56.7)$ & $12(20.0)$ & .513 & .487 & 5.006 & .082 \\
\hline Controls $(n=60)$ & $16(26.7)$ & $31(51.7)$ & $13(21.6)$ & .534 & .467 & 1.0763 & .584 \\
\hline
\end{tabular}

Abbreviations: Hp: haptoglobin; ${ }^{2}$ : chi-square

Table 6. Serum levels of inflammatory markers in relation to Hp phenotypes in type 2 diabetics and healthy non-diabetic subjects

\begin{tabular}{lllllll}
\hline & \multicolumn{3}{c}{ patients } & \multicolumn{3}{c}{ healthy non-diabetic subjects } \\
\cline { 2 - 7 } & Hp1-1 & Hp2-1 & Hp2-2 & Hp1-1 & Hp2-1 & Hp2-2 \\
\hline Hp (mg/dl) & $116.2 \pm 15.0$ & $123.4 \pm 14.2$ & $123.2 \pm 14.2$ & $83.04 \pm 9.2$ & $84.6 \pm 15.3$ & $85.94 \pm 8.0$ \\
& & $\mathrm{P}=0.313$ & $\mathrm{P}=.402$ & & $\mathrm{P}=.775$ & $\mathrm{P}=.519$ \\
hs-CRP (mg/l) & \multirow{2}{*}{$1.84 \pm 0.4$} & $2.07 \pm .0 .14$ & $2.19 \pm .0 .3$ & $1.55 \pm .0 .4$ & $1.71 \pm 0.7$ & $1.94 \pm 0.9$ \\
& & $\mathrm{P}=.525$ & $\mathrm{P}=.595$ & & $\mathrm{P}=.471$ & $\mathrm{P}=.240$ \\
$\mathrm{IL}-6(\mathrm{ng} / \mathrm{ml})$ & $7.46 \pm 1.7$ & $7.80 \pm 1.1$ & $7.84 \pm 1.1$ & $4.72 \pm 1.8$ & $5.06 \pm 1.7$ & $4.96 \pm 1.9$ \\
& & $\mathrm{P}=.624$ & $\mathrm{P}=.629$ & & $\mathrm{P}=.640$ & $\mathrm{P}=.805$ \\
\hline
\end{tabular}

Data expressed as mean \pm SD

No significant difference observed when comparing Hp2-1 vs. Hp 1-1 OR Hp2-2 vs. Hp 1-1 (p-value > 0.05) in patients and healthy nondiabetic subjects

\subsection{Serum Levels of Inflammatory Markers in Relation to Hp Phenotypes}

Table 6 demonstrates the relationship between Hp phenotypes (Hp 1-1, Hp 2-1, Hp 2-2) and serum concentrations of IL-6 $(\mathrm{ng} / \mathrm{mL}), h s-\mathrm{CRP}(\mathrm{mg} / \mathrm{L}), \mathrm{Hp}(\mathrm{mg} / \mathrm{dL})$ in type 2 diabetic patients and control subjects. This study couldn't reveal any significant differences $(p>0.05)$ between the Hp phenotypes and any of these inflammatory markers.

\section{Discussion}

During the last few years, the role of inflammatory factors in type 2 diabetes has become focus of great interest (Ebeling et al., 2001; Greenfield \& Campbell, 2006; Donath \& Shoelson, 2011). In this report, we have shown significantly higher serum concentrations of inflammatory markers (IL-6, hs-CRP, and Hp) in type 2 diabetics compared to controls. Our finding is in agreement with recently published reports which documented strong associations between type 2 diabetes and the mentioned acute phase proteins (Campenhout et al., 2006; Mirza et al., 2012). These findings may support the hypothesis that individuals who progress to type 2 diabetes show features of low-grade inflammation years in advance of disease onset which has been proposed to be involved in the pathogenetic processes causing the disease (Kristiansen \& Mandrup-Poulsen, 2005). Interestingly, insulin itself is an inhibitor of acute-phase protein synthesis and in animal models of diabetes; the acute-phase response is increased by insulin deficiency indicating that there could be a positive feedback whereby cytokine-induced insulin resistance further augments the acute-phase response (Pickup 2004). Moreover, increasing evidence indicates that chronic mild inflammation linked to obesity is closely associated with the development of IR (Ouchi \& Walsh, 2007). On the other hand, IR is strongly associated with obesity and is believed to precede the impairment in insulin secretion (Libman \& Arslanian, 2007). This study demonstrated a significant association between the investigated inflammatory markers (Hp \& $h s$-CRP) and body mass index as a marker of obesity. In consistent with our finding, it has been positively correlated human obesity with blood levels of CRP (Deepa et al., 2006) and Hp (Chiellini et al., 2004; Engstrom et al., 2004). The mechanisms for the significant associations between these acute phase proteins and obesity are unclear, but several explanations are possible. Subcutaneous and intra-abdominal adipose tissue is a major source of IL-6 production, which in turn stimulates the liver synthesis of C-reactive protein and haptoglobin (Pickup, 2004; Samara et al., 2008). Another explanation considered adipose tissues as active endocrine tissues which produce haptoglobin as well as other adipokines like IL-6 (Doumatey et al., 2010). The latter explanation can be supported by the findings of Fain et al (2004) who 
demonstrated a direct proportional release of Hp with IL-6 by explants of human visceral and subcutaneous adipose tissue in primary culture. Moreover, consistent with previous reports (Kado et al., 1999; Rodri'guez-Mora'n et al., 1999; Tan et al., 2004; Suzuki et al., 2009), data demonstrates positive correlations between serum concentration of the examined inflammatory markers and selected variables (serum glucose and $\mathrm{HbA1c)}$.

Several studies have related Hp polymorphism to susceptibility and outcome in important diseases including diabetes (Wobeto et al., 2007; Koda et al., 2008; Costacou et al., 2008). However, this association between the Hp gene and diabetes varies between populations (Quaye et al., 2006). In this study data showed that the Hp1 allele frequencies among Saudi diabetics and healthy subjects were 0.513 and 0.534 respectively. In addition, it is documented that the Hp 2-1 was the most frequent Hp phenotype among Saudi type 2 diabetics. In contrast to our finding, Hp 2-2 was determined as the most common polymorphism in European diabetic population (Asleh et al., 2008). This may be attributed to the dramatic changes in the Saudi population lifestyle which accelerate the onset of type 2 diabetes since Hp 2-1 was the predominant Hp phenotype as reported by Awadallah et al (2001) for a Saudi sample population ( $\mathrm{n}=1002)$ in Southern Saudi Arabia.

It has been reported an association of Hp concentration with its phenotypes (Kasvosve et al., 2000). However, in our study, serum Hp concentrations among patients and control subjects were free of phenotypic-dependence. Moreover, data did not show any significant associations between $h s$-CRP/IL-6 and Hp phenotypes as reported by Bessa et al. (2007). The likely explanation regarding $h s$-CRP could be related to genetic variations of CRP genes and stimulants (such as obesity and low levels of physical activity) which may require different mechanisms. Also it was reported that CRP levels were age dependent increasing gradually to very old age to approximately $3 \mathrm{mg} / \mathrm{L}$ (Kluft et al., 2003). Further research is needed to elucidate the potential mechanism underlying the association between haptoglobin phenotypes and changes in CRP and IL-6 levels.

\section{Conclusion}

The major findings observed in the present study conducted in Saudi populations as follows: (i) Serum levels of IL-6, hs-CRP, and Hp were significantly increased in type 2 diabetics, (ii) obesity (measured by BMI) was associated with inflammatory markers $h s$-CRP and Hp in the diabetic patients, (iii) Serum concentration of the examined inflammatory markers was positively correlated with blood glucose and HbA1c, (iv) The Hp 2-1 phenotype was the predominant phenotype among Saudi both type 2 diabetics and healthy subjects, (v) there was no association documented between the Hp phenotypes and serum concentrations of the three aforementioned inflammatory biomarkers.

\section{References}

Asleh, R., Blum, S., Litman, S. K., Alshiek, J., Miller-Lotan, R., Asaf, R., ... Levy, A. P. (2008). Correction of HDL Dysfunction in Individuals with Diabetes and the Haptoglobin 2-2 Genotype. Diabetes, 57, 2794-2800. http://dx.doi.org/10.2337/db08-0450

Alvarez-Blasco, F., Martınez-Garcıa, M. A., Luque-Ramırez, M., Parraza, N., San Millan, J. L., \& Escobar-Morreale, H. F. (2009). Role of Haptoglobin in Polycystic Ovary Syndrome (PCOS), Obesity and Disorders of Glucose Tolerance in Premenopausal Women. PLoS ONE, 4(5), e5606. http://dx.doi.org/10.1371/journal.pone.0005606.

Awadallah, S., Hamad, M., \& Kadumi, O. (2001). Phenotype Distribution and normal values of Haptoglobin in Asir Region of Southern Saudi Arabia. Bahrain Medical Bulletin, 23, 8-11.

Bessa, S. S., Hamdy, S. M., \& Ali, M. M. (2007). Haptoglobin gene polymorphism in type 2 diabetic patients with and without nephropathy: An Egyptian study. European Journal of Internal Medicine, 18, 489-495. http://dx.doi.org/10.1016/j.ejim.2007.02.033

Burbea, Z. V., Nakhoul, F., Rosenberg, S., Zoabi, R., Skorecki, K., Hochberg, I., ... Levy AP (2004). Role of Haptoglobin Phenotype in End-Stage Kidney Disease. Nephron Experimental nephrology, 97, e71-e76. http://dx.doi.org/10.1159/000078408

Campenhout, A. V., Campenhout, C. V., Lagrou, A. R., Abrams, P., Moorkens, G., Gaal, L. V., \& Manuel-y-Keenoy, B. (2006). Impact of diabetes mellitus on the relationships between iron, inflammatoryand oxidative stress status. Diabetes/Metabolism Research and Reviews, 22, 444-454. http://dx.doi.org/10.1002/dmrr.635

Chiellini, C., Santini, F., Marsili, A., Berti, P., Bertacca, A., Pelosini, C., ... Maffei, M. (2004). Serum Haptoglobin: A Novel Marker of Adiposity in Humans. Journal of Clinical Endocrinology \& Metabolism, 
89, 2678-2683. http://dx.doi.org/10.1210/jc.2003-031965

Costacou, T., Ferrell, R. E., \& Orchard, T. J. (2008). Haptoglobin Genotype: A Determinant of Cardiovascular Complication Risk in Type 1 Diabetes. Diabetes, 57, 1702-1706. http://dx.doi.org/10.2337/db08-0095

Dasgupta, S., Samtani, R., Saraswathy, K.N. (2008). Haptoglobin Polymorphism among Warli Tribe of Dadra Nagar Haveli, India. Anthropologist, 10, 315-316.

Deepa, R., Velmurugan, K., Arvind, K., Sivaram, P., Sientay, C., Uday, S., \& Mohan V. (2006). Serum levels of interleukin 6, C-reactive protein, vascular cell adhesion molecule 1, and monocyte chemotactic protein 1 in relation to insulin resistance and glucose intolerance - the Chennai Urban Rural Epidemiology Study (CURES). Metabolism Clinical and Experimental, 55, 1232-1238. http://dx.doi.org/10.1016/j.metabol.2006.05.008

Delanghe, J. R. \& Langlois, M. R. (2002). Haptoglobin polymorphism and body iron stores. Clinical Chemistry and Laboratory Medicine, 40, 212-216. http://dx.doi.org/10.1515/CCLM.2002.035

Donath, M. Y., \& Shoelson, S. E. (2011). Type 2 diabetes as an inflammatory disease. Nature Reviews Immunology, 11, 98-107. http://dx.doi.org/10.1038/nri2925

Doumatey, A. P., Lashley, K. S., Huang, H., Zhou, J., Chen, G., Amoah, A., ... Rotim, C. (2010). Relationships Among Obesity, Inflammation, and Insulin Resistance in African Americans and West Africans. Obesity, 18, 598-603. http://dx.doi.org/10.1038/oby.2009.322

Ebeling, P., Teppo, A., Koistinen, H. A., \& Koivisto, V. A. (2001). Concentration of the Complement Activation Product, Acylation-Stimulating Protein, Is Related to C-Reactive Protein in Patients With Type 2 Diabetes. Metabolism, 50, 283-287. http://dx.doi.org/10.1053/meta.2001.21032

Engstrom, G., Hedblad, B., Stavenow, L., Jonsson, S., Lind, P., Janzon, L., \& Lindgarde, F. (2004). Incidence of Obesity-Associated Cardiovascular Disease is related to Inflammation-Sensitive Plasma Proteins: A Population-Based Cohort Study, Arteriosclerosis. Thrombosis, and Vascular Biology, 24, 1498-1502. http://dx.doi.org/10.1161/01.ATV.0000134293.31512.be

Fain, J. N., Bahouth, S. W., \& Madan, A. K. (2004). Haptoglobin release by human adipose tissue in primary culture. Journal of Lipid Research, 45, 536-542. http://dx.doi.org/10.1194/jlr.M300406-JLR200

Greenfield, J. R., \& Campbell, L.V. (2006). Relationship between inflammation, insulin resistance and type 2 diabetes: 'cause or effect'?. Current Diabetes Reviews, 2, 195-211. http://dx.doi.org/10.2174/157339906776818532

Hasan, M., Mohieldein, A., Alzohairy, M., \& khan, M. (2012). Human haptoglobin phenotypes on native PAGE using tetramethylphenylenediamanie (TMPD) staining. International Journal of Biological \& Medical Research, 3, 1342-1344.

Kado, S., Nagase, T., \& Nagata, N. (1999). Circulating levels of interleukin-6, its soluble receptor and interleukin-6/interleukin-6 receptor complexes in patients with type 2 diabetes mellitus. Acta Diabetol., 36, 67-72. http://dx.doi.org/10.1007/s005920050147

Kasvosve, I., Gomo, Z. A. R., Gangaidzo, I. T., Mvundura, E., Saungweme, T., Moyo, V. M., ... Delanghe, J. R. (2000). Reference range of serum haptoglobin is haptoglobin phenotype-dependent in blacks. Clinica Chimica Acta, 296, 163-170. http://dx.doi.org/10.1016/S0009-8981(00)00225-4

Kluft, C., \& de Maat, M. P. M. (2003). Genetics of C-Reactive Protein. New Possibilities and Complications. Arteriosclerosis, Thrombosis, and Vascular Biology, 23, 1956-1959. http://dx.doi.org/10.1161/01.ATV.0000 100113.47260.EB

Koda, Y., Yamagishi, S., Amano, S., Okamoto, T., Inagaki, Y., \& Yamada, K. (2008). Haptoglobin genotype and diabetic microangiopathies in Japanese diabetic patients. Diabetologia, 45, 1039-1040.

Kristiansen, O. P., \& Mandrup-Poulsen, T. (2005). Interleukin-6 and Diabetes. The Good, the Bad, or the Indifferent? Diabetes, 54(2), S114-124. http://dx.doi.org/10.2337/diabetes.54.suppl_2.S114

Libman, I. M., \& Arslanian, S. A. (2007). Prevention and Treatment of Type 2 Diabetes in Youth. Hormone Research Paediatrics, 67, 22-34. http://dx.doi.org/10.1159/000095981

Maiese, K., Shang, Y. C., Chong, Z. Z., \& Hou, J. (2010). Diabetes Mellitus: Channeling Care through Cellular Discovery. Current Neurovascular Research, 7, 59-64. http://dx.doi.org/10.2174/156720210790820217

Mirza, S., Hossain, M., Mathews, C., Martinez, P., Pino, P., Gay, J. L., \& Fisher-Hoch, S. P. (2012). Type 2-diabetes is associated with elevated levels of TNF-alpha, IL-6 and adiponectin and low levels of leptin in a population of Mexican Americans: A cross-sectional study. Cytokine, 57, 136-142. 
http://dx.doi.org/10.1016/j.cyto.2011.09.029

Mishra, S. P., Siddiqi, S. S., \& Nkagrawal, K. A. (2010). Polymorphism Of Human Haptoglobin and Its Importance In Diabetic Nephropathy. Digest Journal of Nanomaterials and Biostructures, 5, 599-603.

Mohieldein, A., Alzohairy, M., \& Hasan, M. (2011). Risk estimation of type 2 diabetes and dietary habits among adult Saudi Non-diabetics in Central Saudi Arabia. Global Journal of Health Science, 3, 123-133. http://dx.doi.org/10.5539/gjhs.v3n2p123

Ouchi, N., \& Walsh, K. (2007). Adiponectin as an anti-inflammatory factor. Clinica Chimica Acta, 380, 24-30.

Pickup, J. C. (2004). Inflammation and activated innate immunity in the pathogenesis of type 2 diabetes. Diabetes Care, 27, 813-823. http://dx.doi.org/10.2337/diacare.27.3.813

Pradhan, A. D., \& Ridker, P. M. (2002). Do atherosclerosis and type 2 diabetes share a common inflammatory basis?. European Heart Journal, 23, 831-834. http://dx.doi.org/10.1053/euhj.2001.3052

Quaye, I. K., Ababio, G., \& Amoah, A. G. (2006). Haptoglobin 2-2 phenotype is a risk factor type 2 diabetes in Ghana. Journal Atherosclerosis and Thrombosis, 13, 90-94. http://dx.doi.org/10.5551/jat.13.90

Quaye, I. K. (2008). Haptoglobin, inflammation and disease. Transactions of the Royal Society of Tropical Medicine and Hygiene, 102, 735-742. http://dx.doi.org/10.1016/j.trstmh.2008.04.010

Rodrı'guez-Moran, M., \& Guerrero-Romero, F. (1999). Increased Levels of C-Reactive Protein in Noncontrolled Type II Diabetic Subjects. Journal of Diabetes and Its Complications, 13, 211-215. http://dx.doi.org/10.1016/S1056-8727(99)00047-1

Samara, A., Pfister, M., Marie, B., \& Visvikis-Siest, S. (2008). Visfatin, low-grade inflammation and body mass index (BMI). Clinical Endocrinology, 69, 568-574. http://dx.doi.org/10.1111/j.1365-2265.2008.03205.x

Schwarz, P. E. H., Schwarz, J., Schuppenies, A., Bornstei, S. R., \& Schulze, J. (2007). Development of a Diabetes Prevention Management Program for Clinical Practice. Public Health Rep., 122, $258-263$. http://www.ncbi.nlm.nih.gov/pmc/articles/PMC1820432/

Suzuki, K., Yagi, K., Oka, R., Saiki, Y., Kubota, M., Suzuki, Masako, S. ... Junji, K. (2009). Relationships of serum haptoglobin concentration with $\mathrm{HbAlc}$ and glycated albumin concentrations in Japanese type 2 diabetic patients. Clin Chem Lab Med, 47, 70-4. http://dx.doi.org/10.1515/CCLM.2009.022

Tan, K, C. B., Chow, W. C., Tam, S., Bucala, R., \& Betteridge, J. (2004). Association between Acute-Phase Reactants and Advanced Glycation End Products in Type 2 Diabetes. Diabetes Care, 27, $223-228$. http://dx.doi.org/10.2337/diacare.27.1.223

Vitalis, Z., Altorjay, I., Tornai, I., Palatka, K., Kacska, S., Palyu, E., ... Papp, M. (2011). Phenotypic polymorphism of haptoglobin: A novel risk factor for the development of infection in liver cirrhosis. Human Immunology, 72, 348-354. http://dx.doi.org/10.1016/j.humimm.2011.01.008

Wobeto, V. P. A., Rosim, E. T., Melo, M. B., Calliari, L. E. P., \& Sonati, M. F. (2007). Haptoglobin polymorphism and diabetic retinopathy in Brazilian patients. Diabetes Research and Clinical Practice, 77, 385-388. http://dx.doi.org/10.1016/j.diabres.2006.12.018

Wobeto, V. P., Garcia, P. M., Zaccariotto, T. R., \& Sonati, M. F. (2009). Haptoglobin polymorphism and diabetic nephropathy in Brazilian diabetic patients. Annals of Human Biology, 36, 437-441. http://dx.doi.org/10.1080/03014460902960263

World Health Organization. (1995). Physical status: the use and interpretation of anthropometry: report of a WHO expert committee. World Health Organ Tech Rep Ser, 854, 1-452

\section{References to a web source:}

Report of the Expert Committee on the Diagnosis and Classification of Diabetes Mellitus. (2002). Diabetes Care, 25(1), s5-s20. http://dx.doi.org/10.2337/diacare.25.2007.S5 Diabetes 